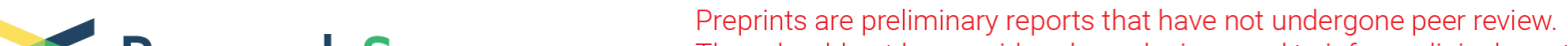 Research Square They should not be considered conclusive, used to inform clinical practice, or referenced by the media as validated information.
}

\section{SNX17 regulates antigen internalization and phagosomal maturation by dendritic cells}

Ignacio Cebrian ( $\square$ icebrian@mendoza-conicet.gob.ar)

IHEM-CONICET, Universidad Nacional de Cuyo https://orcid.org/0000-0001-6505-0875

\section{Sofía Dinamarca}

IHEM-CONICET, Universidad Nacional de Cuyo

Cristina Croce

IHEM-CONICET, Universidad Nacional de Cuyo

\section{Anna Salvioni}

Institut Toulousain des Maladies Infectieuses et Inflammatoires (Infinity)

\section{Facundo Garrido}

IHEM-CONICET, Universidad Nacional de Cuyo

\section{Sandra Estrada Fidalgo}

IHEM-CONICET, Universidad Nacional de Cuyo

\section{Luis Mayorga}

IHEM-CONICET, Universidad Nacional de Cuyo

Nicolas Blanchard

Institut Toulousain des Maladies Infectieuses et Inflammatoires (Infinity) https://orcid.org/0000-00024924-2161

\section{Article}

Keywords: SNX17, dendritic cells, antigen internalization, phagosomal maturation

Posted Date: January 18th, 2021

DOl: https://doi.org/10.21203/rs.3.rs-144634/v1

License: (c) (1) This work is licensed under a Creative Commons Attribution 4.0 International License.

Read Full License 


\section{Abstract}

Cross-presentation is the process whereby antigenic peptides derived from exogenous antigens are associated to $\mathrm{MHC}$ class I molecules triggering the activation of CD8+ T lymphocytes. The endocytic route of dendritic cells (DCs) is strongly specialized to achieve antigen cross-presentation efficiently, which is crucial to initiate cytotoxic immune responses against many pathogens (i.e. Toxoplasma gondii) and tumors. Nevertheless, the endosomal molecular effectors involved in this process are not completely understood. In particular, the role of sorting nexin (SNX) proteins in cross-presentation has never been addressed. In this work, we identify the endosomal protein SNX17 as a key regulator of antigen internalization and cross-presentation by DCs. Our results demonstrate that SNX17 expression in DCs is essential to guarantee a normal cross-presentation of soluble, particulate and T. gondii-associated antigens. The silencing of SNX17 expression in DCs significantly affected the uptake of exogenous antigens by fluid-phase endocytosis and phagocytosis, but not by receptor-mediated endocytosis. Moreover, the knock-down of SNX17 impaired T. gondii invasion, CD11b integrin recycling and hampered the organization of the actin cytoskeleton. Finally, we show that SNX17 controls the proper maturation of DC phagosomes. Our findings provide compelling evidence that SNX17 plays a central role in the modulation of DC endocytic network, which is crucial for competent antigen internalization and crosspresentation.

\section{Introduction}

Dendritic cells (DCs) are the most adapted antigen-presenting cells (APCs) of the immune system for efficient cross-presentation. This implies the internalization of exogenous antigens, their intracellular processing and loading onto MHC-I molecules to present antigenic peptides to CD8+ T lymphocytes. ${ }^{1}$ To do this, DCs have developed important specializations of their endocytic network that include a tight regulation of endo/phagosomal maturation, ${ }^{2}$ a special connection between endosomes and phagosomes with the endoplasmic reticulum (ER) ${ }^{3,4}$ and a recycling pathway for MHC-I molecules. ${ }^{5}$ Furthermore, the process of endosomal tubulation is starting to emerge as a key modulator of antigen cross-presentation by DCs. ${ }^{6,7}$

In this sense, sorting nexins (SNXs) are master regulators of intracellular transport by leading elongation and tubulation of endosomal membranes. ${ }^{8}$ This family of effectors is constituted of both cytoplasmic and membrane-associated proteins that control important features of the endocytic pathway, including endocytosis, endosomal sorting, and signaling. ${ }^{9} \mathrm{SNXs}$ are characterized by the presence of a particular type of phox-homology (PX) domain, the SNX-PX domain. ${ }^{10}$ As PX domains function mostly by binding phosphatidylinositol-3-monophosphate (Ptdlns3P), SNXs are associated with Ptdlns3P-enriched elements of the early endocytic network. ${ }^{10,11}$ Although SNX proteins ensure critical functions that are relevant for antigen cross-presentation, their potential role in this immunological context has never been addressed. 
We focused our study on the role of SNX17 within the endocytic network of DCs, with particular interest in antigen cross-presentation. In addition to the PX domain, SNX17 has an atypical FERM domain able to interact with many cargoes that contain an NPxY/NxxY motif. ${ }^{12}$ Therefore, SNX17 is involved in the recycling of integrins in different biological models, such as cell adhesion and migration, ${ }^{13,14}$ in association with the retriever complex ${ }^{15}$ or contributing to the establishment of the immune synapse by $T$ cells. ${ }^{16}$ SNX17 was also reported to facilitate papillomavirus infection through the interaction with the L2 capsid protein and to allow viral escape from late endosomal compartments. ${ }^{17}$

Here, we show that SNX17 controls the process of antigen cross-presentation by DCs. Indeed, we demonstrate that SNX17 regulates integrin recycling also in this cell type, but is not implicated in MHC-I recycling. Upon silencing the expression of SNX17 in DCs, fluid-phase endocytosis and phagocytosis are remarkably inhibited. Strikingly, Toxoplasma gondii invasion is hampered in SNX17-deficient DCs, reporting the first host endocytic effector that supports infection by this parasite. We also show that SNX17 is required for the proper organization of the actin cytoskeleton and for phagosomal maturation, highlighting this molecule as a critical regulator of DC endocytic network.

\section{Results}

\section{The silencing of SNX17 in DCs impairs antigen cross-presentation}

As part of a larger screen aiming to find novel regulators of $T$. gondii antigen presentation by $\mathrm{MHC}-\mathrm{I}$ molecules, we identified SNX17 as a key player in this process. Upon SNX17 silencing by lentiviral shRNAs, we found that MutuDCs, a murine CD8a ${ }^{+} D C$ line, ${ }^{18}$ were unable to cross-present antigens from the two T. gondii strains we tested, as compared to control MutuDCs (Scramble shRNA). These type I $T$. gondii strains express model MHC-I antigens that both contain an antigenic peptide, the SIINFEKL epitope from the ovalbumin (OVA) protein, and are secreted in the vacuole. However, these antigens exhibit different intra-vacuolar distribution, leading to distinct presentation pathways. ${ }^{19}$ In the SAG1-OVA strain, the model antigen is a soluble luminal protein, ${ }^{20}$ while in the GRA6-OVA strain, the antigenic construct is a transmembrane protein. ${ }^{21}$ We used two different shRNAs to silence SNX17 expression in DCs and we observed a severe reduction of $T$. gondii presentation on MHC-I molecules with both parasite strains (Fig. $1 \mathrm{a}$ and $1 \mathrm{~b}$ ). Moreover, the cross-presentation ability of the OVA protein incorporated in the MutuDC by endocytosis was strongly impaired in SNX17 knockdown (KD) DCs (Fig. 1C), while the presentation of the short SIINFEKL peptide was affected as well, but to a minimal extent (Fig. 1d). We validated these data by qPCR analysis, and for all antigens tested, the decrease in cross-presentation capacity correlated with the KD efficiency (Fig. 1e).

We next generated two stable SNX17 KD cell lines by using the same shRNAs in JAWS-II DCs. In contrast to MutuDCs, we obtained the highest KD efficacy with the shRNA \#2, as evidenced by Western blot analysis of the transduced JAWS-II DCs (Fig. 1f). We examined MHC-I presentation in these cells and, again, a significant inhibition of cross-presentation was evidenced in both SNX17 KD DCs, either with 
soluble OVA (Fig. 1g) or OVA associated to $3 \mu \mathrm{m}$ latex beads (Fig. 1h). As above, the level of crosspresentation reduction was in line with the efficiency of SNX17 silencing, although in this case, we did not observe any effect on the control SIINFEKL peptide presentation by SNX17 KD DCs, as compared to Scramble DCs (Fig. 1i). Given that the shRNA \#2 exhibited a higher KD and more pronounced differences in antigen cross-presentation, we used this stable line (from now on SNX17 KD cells) to continue our study.

\section{Integrin recycling is blocked in SNX17 KD DCs}

SNX17 was shown to regulate integrin recycling to the cell surface in other biological systems. ${ }^{13-16}$ Thus, we aimed to evaluate if SNX17 also performs a similar function in DCs. First, we analyzed by flow cytometry the cell surface expression level of the $\mathrm{aM} \beta 2$ integrin $\mathrm{CD} 11 \mathrm{~b}$, which is highly expressed in DCs. As shown in Fig. 2a and 2b, SNX17 KD cells display lower levels of CD11b, as compared to control DCs, suggesting a defect of recycling to the plasma membrane. In order to test this hypothesis, we assessed

the endocytic recycling of CD11b by flow cytometry, as described and performed in previous studies. ${ }^{16,22}$ Briefly, the decrease in the mean fluorescent intensity (MFI) of PE-conjugated CD11b antibody was measured to determine the recycling to the cell surface of this integrin after binding, internalization and acid stripping. Indeed, we observed a drastic defect of CD11b recycling by SNX17 KD DCs, as compared to Scramble DCs (Fig. 2c and 2d).

Based on the importance of SNX17 for CD11b integrin recycling and given that MHC-I recycling is a key aspect to guarantee a proper antigen cross-presentation process, ${ }^{5,22-24}$ we hypothesized that SNX17 may also control the recycling of MHC-I molecules. Nevertheless, when we analyzed both the expression level of MHC-I at the cell surface (Fig. 2e and 2f) and the recycling of MHC-I (Fig. $2 \mathrm{~g}$ and 2h), we did not find significant differences between SNX17 KD and Scramble DCs. So far, these data indicate that SNX17 is required for optimal antigen cross-presentation and CD11b integrin recycling by DCs, but is dispensable for the recycling of MHC-I molecules.

\section{Antigen internalization is inhibited in SNX17 KD DCs}

In order to explain the defect in the cross-presentation ability of SNX17 KD DCs, we decided to investigate the first step of this process, which is antigen uptake. To this aim, we first analyzed fluid-phase endocytosis of a fluorescent version of the OVA model antigen by flow cytometry. As shown in Fig. 3a and $3 b$, a significant impairment of OVA uptake at different concentrations compatible with macropinocytosis was observed in SNX17 KD DCs, as compared to control cells. Since this defect could be also explained by an enhancement of OVA degradation inside SNX17 KD cells, we next evaluated the fluid-phase endocytosis of a non-degradable fluorescent antigen (dextran). Again in this experimental setup, the macropinocytic activity of SNX17 KD DCs was significantly altered (Fig. 3c and 3d).

Because there is also an impairment of particulate antigen cross-presentation in SNX17 KD DCs, we then examined the phagocytic activity of these cells. By using fluorescent $3 \mu \mathrm{m}$ latex beads coated with OVA and flow cytometry analysis, we were able to distinguish between cells that completely incorporate these 
particles from those that have beads attached to the surface but not fully internalized. We used this approach to measure the percentage of effective phagocytosis and we determined that SNX17 KD DCs exhibit a marked deficiency in this process at different time points of uptake (1, 3 and 5 hours), as compared to control cells (Fig. 3e and 3f).

Aiming to understand the relevance of SNX17 in the presentation of $T$. gondii antigens, we decided to evaluate whether parasite invasion was affected in the KD cells. We used a fluorescent strain of $T$. gondii (TgRH YFP SAG1-OVA) and an antibody against SAG1 (a parasite surface protein). In this way, we could determine the percentage of infected DCs (YFP+/SAG1- cells) and the percentage of DCs simply bound to extracellular parasites (YFP+/SAG1+ cells). We performed this assay at 3 hours post-infection, a time point that precedes the first parasite replication cycle inside the DCs. Interestingly, while the proportion of DC surface-bound parasites was similar in the two conditions (Fig. S1a), SNX17 KD DCs were much less infected by T. gondii (Fig. $3 g$ and 3 h).

Since all the internalization pathways relevant in our cross-presentation assays (macropinocytosis, phagocytosis and T. gondii invasion) were found to be defective in the SNX17 KD cells, we wondered whether receptor-mediated endocytosis would also be affected by SNX17 silencing. To do this, we measured the internalization of two antigen s by different receptors; $\mathrm{MHC}-\mathrm{I}$ for the uptake of anti-H2 $\mathrm{K}^{\mathrm{b}}$ coupled to FITC (Fig. S1b), and Fc receptor for the uptake of the immune complex fluorescent OVA/antiOVA (Fig. S1C). After the steps of antigen binding to receptor at $4^{\circ} \mathrm{C}$, washing, internalization at $37^{\circ} \mathrm{C}$ and acidic stripping of the cell surface, we determined by flow cytometry that the effective uptake of these antigens was not affected by the silencing of SNX17, indicating that receptor-mediated endocytosis is independent of this endosomal molecule in DCs. Overall, this set of experiments points to SNX17 as a novel and critical regulator of macropinocytosis, phagocytosis and T. gondii infection in DCs.

\section{SNX17 modulates the organization of the actin cytoskeleton}

Since the antigen internalization pathways found to be defective in SNX17 KD cells have in common to be dependent on actin remodeling, we asked whether the actin cytoskeleton may be altered in the KD cells. To test this, we used phalloidin and an antibody against actin to label polymerized filamentous actin (F-actin) and total actin, respectively, and we analyzed the cells by confocal microscopy. In control DCs, we observed that most of the F-actin is around the cell surface with a clear distribution within long dendrites (Fig. 4a, upper panels). By contrast, these long dendrites were mostly absent in SNX17 KD DCs, although F-actin still remained around the cell surface (Fig. 4b, upper panels). We better documented this difference by quantifying the number of dendrites of $3 \mu \mathrm{m}$ or more in Scramble and SNX17 KD cells (Fig. 4c). As expected, the continuous phalloidin staining was lost upon DC treatment with latrunculin $B$, which inhibits actin polymerization (Fig. $4 \mathrm{a}$ and $4 \mathrm{~b}$, lower panels), confirming that the dendrites are F-actinbased.

In order to determine whether the phenotype observed in SNX17 KD cells was due to a defect in actin polymerization or an inaccurate organization of actin remodeling, we quantified F-actin and total actin by 
flow cytometry. As shown in Fig. 4d and 4e, no significant difference was found between KD and control cells, suggesting that SNX17 drives filopodial elongation relevant for macropinocytosis and phagocytosis rather than actin polymerization in DCs. We observed that SNX17 KD DCs were slightly bigger in size than Scramble DCs, exhibiting higher fluorescent background and specific staining, but the phalloidin/actin ratio was similar between both DC types.

\section{Phagosomal maturation is delayed in SNX17 KD DCs}

In addition to perturbing the antigen uptake, a dysregulation of the actin cytoskeleton organization may impact on other important features of DCs during the intracellular transport of exogenous antigens. Hence, we decided to address the role of SNX17 on phagosomal maturation by flow cytometry. After coating $3 \mu \mathrm{m}$ latex beads with OVA and inducing phagocytosis at different time periods $(15,60$ and 180 $\mathrm{min}$ ), we labeled isolated phagosomes with anti-OVA and anti-Lamp1 to measure intra-phagosomal antigen degradation and phago-lysosomal fusion, respectively. While phagosomes recovered from Scramble cells displayed OVA degradation over time, antigen degradation was less efficient in the SNX17 KD-derived phagosomes at 3 hours post-internalization (Fig. $5 a$ and $5 \mathrm{~b}$, left axis). This suggests that phago-lysosomal fusion may be impaired in SNX17 KD DCs. Indeed, phagosomal acquisition of the lysosomal marker Lamp1 was inhibited in SNX17 KD DCs already from 15 min post-internalization, as compared to Scramble phagosomes (Fig. 5c and 5b, right axis).

Altogether, our results demonstrate that SNX17 is in charge of key functions within the endocytic pathway of DCs, mainly by regulating antigen internalization, actin remodeling and phagosomal maturation, all critical events needed to ensure an efficient antigen cross-presentation process.

\section{Discussion}

Different molecular regulators of the endocytic pathway that contribute to the process of antigen crosspresentation have been characterized in the past fifteen years, ${ }^{25}$ but our study is the first to address the role of SNXs in this immunological context. From our original T. gondii presentation screening, we observed that this family of proteins play a key role to achieve efficient MHC-I presentation of parasitederived antigens. Among other interesting candidates that modulate antigen cross-presentation, we identified SNX17 as a positive regulator of this process. Upon DC silencing (we used two different DC lines) of SNX17 expression, we observed a significant reduction of cross-presentation for all exogenous antigens tested derived either from soluble OVA, latex beads or T. gondii.

SNX17 has been described to control important aspects of endocytic recycling, ${ }^{13-16}$ which is a determinant feature that guarantees proper intracellular transport of MHC-I molecules required for crosspresentation. ${ }^{22-24}$ Based on this, our first hypothesis was that SNX17 was implicated in MHC-I recycling. Nevertheless, we did not observe a significant difference between SNX17 KD and control DCs, although $\mathrm{MHC}-\mathrm{I}$ recycling capacity of KD cells was slightly affected. By contrast, the recycling of the $\mathrm{aM} \beta 2$ integrin CD11b in SNX17 KD DCs was drastically impaired, as reported before for several integrins in other cell 
types. ${ }^{13-16}$ Instead of a deficient MHC-I recycling, we detected a strong inhibition of antigen internalization in SNX17 KD DCs. With the exception of receptor-mediated endocytosis, all the internalization pathways tested turned out to be highly dependent on SNX17 in DCs. This discovery was striking, not only because we observed that SNX17 controls the uptake of exogenous antigens by fluidphase endocytosis and phagocytosis, but also because $T$. gondii infection was surprisingly abrogated in SNX17 KD cells.

T. gondii is an obligate intracellular protozoa that establishes life-long chronic infections in up to a third of the world's population and is the causative agent of toxoplasmosis, an opportunistic disease of potential deadly consequences for immunocompromised people and congenitally infected newborns. ${ }^{26}$ This parasite replicates in a specialized parasitophorous vacuole (PV), surrounded by a limiting membrane that restricts access to the nutrient-rich cytoplasm ${ }^{27}$ and interacts with different organelles of the host cell, including ER, mitochondria and endosomal vesicles. ${ }^{28}$ As it grows, the vacuole also has an enormous impact on the microtubule network, which reorganizes around the PV. ${ }^{29}$ Despite the description of these multiple interactions at the PV border, little is known about the host molecular factors controlling them or required for $T$. gondii entry. Although parasite entry is mainly achieved by a parasite-driven mechanism that involves the parasite acto-myosin system, ${ }^{30}$ a normal host actin organization is also required for efficient $T$. gondii penetration. ${ }^{31,32}$ A previous study in human cells, identified six proteins involved in the modulation of host actin dynamics that facilitate T. gondii entry. ${ }^{33}$ More recently, a genome-wide CRISPR-based screen revealed 1183 human genes that are significantly involved in $T$. gondii infection, 53 of them were linked to the regulation of host actin cytoskeleton. ${ }^{34}$ But our study is original because it describes a host cell endosomal protein capable to strongly control the process of $T$. gondii entry, which to our knowledge has not been reported before. This is particularly interesting since at present, there is not effective vaccine or treatment to prevent $T$. gondii infection, thus SNX17 could represent a unique target in order to potentially block the parasite entry. As a first step, it will be important to evaluate the role of SNX17 during T. gondii infection of other cell types, including human DCs.

At least two members of the SNX family, SNX9 $9^{35-37}$ and SNX33, ${ }^{38}$ have been reported to interact with the Wiskott-Aldrich syndrome protein (WASp) inducing changes in actin dynamics and regulating endocytosis. So far, SNX17 has not been implicated to bind with WASp, but the SNX17-retriever complex associates with the WASH complex, ${ }^{15}$ which may impact on vesicular transport through actin remodeling. ${ }^{39}$ Indeed, the drastic disorganization of F-actin observed in our SNX17 KD DCs provides new evidence to support this hypothesis.

A clear demonstration that intracellular actin-mediated transport strongly depends on SNX17 is the significant delay of phagosome maturation in SNX17 KD cells. The inefficient acquisition of lysosomal vesicles by SNX17 KD phagosomes also inhibits intra-phagosomal antigen degradation. In this sense, it was reported that SNX10 promotes phagosomal maturation in macrophages by recruiting the complex Mon1-Ccz1 to endosomes and phagosomes. As consequence, SNX10 deficient macrophages exhibit less acidic phagosomes and a reduced ability to kill the bacteria Listeria monocytogenes. ${ }^{40}$ Also SNX3 is 
efficiently recruited to $\mathrm{DC}$ phagosomes and negatively regulates phagocytic uptake. ${ }^{41}$ Moreover, it was shown in macrophages that SNX3 is transported with Rab5a positive vesicles towards Borrelia burgdorferi-containing phagosomes to promote maturation of these organelles and the spirochete compaction. ${ }^{42}$ Also in macrophages, SNX5 plays an important role during macropinosome biogenesis controlling the uptake and processing of soluble exogenous antigens. ${ }^{43}$ We still do not know whether the difference of phagosomal maturation observed in SNX17 KD DCs enhances or partially restores the phenotype of cross-presentation found in these cells.

Taking into account that SNX17 actively participates in antigen and $T$. gondii internalization by DCs to trigger CD8+ T cell-mediated responses, we consider that this molecule could represent a key target for future immunotherapy approaches based on DC stimulation and for new therapeutic strategies against $T$. gondii infection.

\section{Materials And Methods}

\section{Cells}

MutuDCs were maintained with IMDM medium supplemented with $8 \%$ FBS and were provided by $\mathrm{H}$. Acha-Orbea through an MTA with N. Blanchard. JAWS-II DCs were maintained in culture by using GMCSF-containing medium (IMDM) with 10\% FBS. The cytokine GM-CSF was produced with the cell line J558, also maintained in IMDM medium. Both, JAWS-II and J558 cells, were kindly provided by S. Amigorena (INSERM U932, Institute Curie, France). MutuDCs and JAWS-II DCs were expanded and diluted every 2-4 days, depending on their growth rates. T. gondii parasites were grown through continuous infection of Human Foreskin Fibroblasts (HFF), which were maintained in DMEM complete medium (10\% FBS). B3Z T cells were cultured with RPMI complete medium (10\% FBS).

\section{Material and buffers}

The following reagents were used in this study: Ovalbumin, lyophilized powder (Worthington Biochemical Corporation). Bovine Serum Albumin (BSA) was purchased from Santa Cruz. $3 \mu \mathrm{m}$ latex beads and $3 \mu \mathrm{m}$ blue latex beads (Polysciences Inc.). OVA peptide 257-264, SIINFEKL (Polypeptide Group). OVA conjugated to Alexa 488 or 647 and dextran conjugated to Alexa 647 (Invitrogen). IMDM, DMEM and RPMI media (Gibco). Poly-L-lysine, saponin, sucrose, protease inhibitor cocktail, latrunculin B, shRNAs and qPCR primers (Sigma-Aldrich). Ammonium persulfate (Bio Basic Inc.). Tricine, Tris Base, and TEMED (Calbiochem). Glycine (Bio-Rad). Acrylamide (Promega). Imidazole and NP-40 (ICN Biomedicals Inc.).

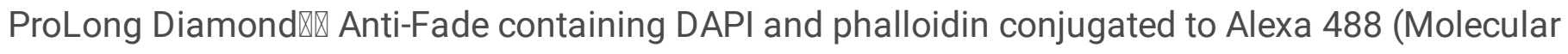
Probes, Life Technologies). Fetal Bovine Serum (FBS) was purchased in Natocor - Industria Biológica (Argentina).

\section{Antibodies}


The following antibodies were used in this study: mouse monoclonal anti-SNX17 (Santa Cruz), mouse monoclonal anti- $\beta$-actin and purified rabbit polyclonal anti-OVA (Sigma-Aldrich), purified rat anti-Lamp1, PE rat anti-CD11b and FITC mouse anti-H-2K ${ }^{\mathrm{b}}$ (BD Pharmingen), mouse monoclonal anti-SAG1 (Santa Cruz). Anti-species conjugated to Alexa 488, 568, or 647 (Molecular Probes) or peroxidase (Jackson Laboratories) were used as secondary antibodies.

\section{Lentiviral shRNA knockdown of SNX17}

High titer lentiviral particles ( 107 CFU/ml) were purchased from Sigma-Aldrich. SNX17 \#1 shRNA (TRCN0000190245, target sequence CCGGCCTCTACCTGAGAGGAGATTTC TCGAGAAATCTCCTCTCAGGTAGAGGTTTTTTG), SNX17 \#2 shRNA (TRCN0000190340, target sequence CCGGCCAGATGACTTGATCGGATATCTCGAG ATATCCGATCAAGTCATCTGGTTTTTTG) and the control hairpin (a scramble sequence against GFP) were used to infect Mutu or JAWS-II DCs. Briefly, 5x104 MutuDCs or $10^{5}$ JAWS-II DCs were plated on a 96-well plate with $200 \mu \mathrm{l}$ of their corresponding complete medium. After $48 \mathrm{~h}$, the medium was carefully removed and $10 \mu \mathrm{l}$ of virus was added. Cell pellet was mixed by resuspending 3-5 times with a pipette and $40 \mu \mathrm{l} \mathrm{of} 8 \mu \mathrm{g} / \mathrm{ml}$ polyB in complete medium was added. Cells were centrifuged during $90 \mathrm{~min}$ at $800 \mathrm{~g}$ and $37^{\circ} \mathrm{C}$, all media were removed and replaced by $200 \mu \mathrm{l}$ of fresh complete medium. Cells were incubated for $48 \mathrm{~h}$, selected with puromycin at $5 \mu \mathrm{g} / \mathrm{ml}$ or 20 $\mu \mathrm{g} / \mathrm{ml}$ for MutuDCs and JAWS-II DCs, respectively. Mutu DCs were transiently infected and collected for experiments $72 \mathrm{~h}$ after puromycin selection. In the case of JAWS-II cells, they were expanded until the generation of stable KD cell lines.

\section{qPCR}

Cell homogenization and RNA extraction were performed by using the TRIzol Reagent protocol (Invitrogen). After determining RNA concentration, cDNA was produced with the iScript cDNA Synthesis Kit (Bio-Rad) and PCR amplification was performed by using 5x HOT FIREPol EvaGreen qPCR Mix (Solis BioDyne) during 40 cycles. GAPDH/SNX17 normalization was done by midpoint slope determination.

\section{Immunoblotting}

Total cell lysates from JAWS-II DCs $\left(10^{5}\right.$ cells, around $50 \mu \mathrm{g}$ of proteins) were subjected to SDS-PAGE on $10 \%$ gel. After transferring, the membranes were blocked in 10\% Milk/PBS during 1 hour and incubated with anti-SNX17, anti- $\beta$-actin and then with peroxidase-conjugated antibodies. Bound antibodies were revealed using the kit Chemiluminescent Peroxidase Substrate-3 (Sigma-Aldrich), according to the manufacturers' instructions. The intensity of the bands was quantified by densitometry using Quantity One 4.6.6 software (Bio-Rad) and was expressed as arbitrary units.

\section{Antigen cross-presentation assays}

MutuDCs were infected with TgRH GRA6-SL 8 or TgRH YFP SAG1-OVA parasites during $8 \mathrm{~h}$ at $37^{\circ} \mathrm{C}$. Previously, T. gondii parasites were released from the HFF cells by forcing them through a 23-G needle 
and added to Scramble and SNX17 KD1 and KD2 MutuDCs at the indicated multiplicity of infection (MOI). These cells were also incubated during $5 \mathrm{~h}$ with $1.5,3$ or $6 \mathrm{mg} / \mathrm{ml}$ of soluble OVA, or during $1 \mathrm{~h}$ with different concentrations of the SIINFEKL peptide at $37^{\circ} \mathrm{C}$. In the case of JAWS-II DCs, Scramble and SNX17 KD cells were incubated during $5 \mathrm{~h}$ with 3 or $6 \mathrm{mg} / \mathrm{ml}$ of soluble OVA, or with $3 \mu \mathrm{m}$ latex beads coated with different ratios of OVA and BSA (OVA $10 \mathrm{mg} / \mathrm{ml}$ alone; OVA $3 \mathrm{mg} / \mathrm{ml}-B S A 7 \mathrm{mg} / \mathrm{ml}$; and BSA $10 \mathrm{mg} / \mathrm{ml}$ alone), or during $1 \mathrm{~h}$ with the indicated doses of SIINFEKL at $37^{\circ} \mathrm{C}$. Then, MutuDCs and JAWS-II DCs were washed with $0.5 \%$ of PBS/BSA, fixed with $0.008 \%$ glutaraldehyde during 3 min at $4^{\circ} \mathrm{C}$, and quenched with $0.2 \mathrm{M}$ glycine. After one final wash with PBS, B3Z hybrid T cells were added during $16 \mathrm{~h}$ at $37^{\circ} \mathrm{C}$. T cell activation was measured detecting $\beta$-galactosidase activity by optical density (absorbance at 595-655 nm) using CPRG as substrate for the reaction.

\section{Recycling experiments}

JAWS-II DCs were surface labeled either with anti-H-2K ${ }^{b}$ FITC-coupled or anti-CD11b PE-coupled for 30 min at $4^{\circ} \mathrm{C}$ (binding). After extensive washing with $0.5 \% \mathrm{PBS} / \mathrm{BSA}$, cells were incubated during $30 \mathrm{~min}$ at $37^{\circ} \mathrm{C}$ in complete medium to allow internalization of the fluorescent antibodies. Cells were pelleted and resuspended in acid buffer stripping solution $(0.5 \mathrm{M} \mathrm{NaCl}$ and $0.5 \%$ acetic acid, $\mathrm{pH} 3)$ for $10 \mathrm{~min}$ on ice. Then, they were washed twice with cold PBS and twice with complete medium (pulse), resuspended in complete medium and incubated at $37^{\circ} \mathrm{C}$ for $0,10,20$, and 40 min (chase) to allow recycling of MHC-I and CD11b to the cell surface. After each time period, DCs were treated again in acid buffer stripping solution for 10 min on ice, washed, and fixed with 1\% PFA. The MFI of FITC and PE were analyzed by FACS, and the percentage of recycled MHC-I and CD11 b was measured by using the equation $\left(\mathrm{T}_{0}-\right.$ $\left.T_{x}\right) / T_{0} \times 100 . T_{0}$ represents the MFI of cells at 0 min, and $T_{x}$ is the MFI of cells at 10,20 , and 40 min.

\section{Antigen uptake and $T$. gondii infection assays}

Scramble and SNX17 KD JAWS-II DCs were incubated during $1 \mathrm{~h}$ at $37^{\circ} \mathrm{C}$ either with OVA or dextran conjugated to Alexa 647 in complete medium at the indicated concentrations. The incubation at $4^{\circ} \mathrm{C}$ with the highest concentration of these soluble antigens was performed as negative control for endocytosis. Then, cells were washed with $0.5 \%$ PBS/BSA and the MFI for every condition was calculated by flow cytometry analysis.

To determine the phagocytic capacity of Scramble and SNX17 KD DCs, JAWS-II cells were incubated with OVA-coated $3 \mu \mathrm{m}$ blue latex beads in complete medium during 1,3 and $5 \mathrm{~h}$ at $37^{\circ} \mathrm{C}$ or during $5 \mathrm{~h}$ at $4^{\circ} \mathrm{C}$. After these internalization time periods, cells were extensively washed with $0.5 \%$ PBS/BSA, labeled first with anti-OVA and then with a secondary anti-rabbit conjugated to Alexa 488. Finally, DCs were analyzed by flow cytometry and the percentage of cells with fluorescent beads fully internalized was determined, as shown in Fig. $3 e$ and $3 f$.

For T. gondii infection experiments, Scramble and SNX17 KD JAWS-II DCs were incubated with TgRH YFP SAG1-OVA parasites at the indicated MOls during $8 \mathrm{~h}$ at $37^{\circ} \mathrm{C}$. Then, DCs were washed with $0.5 \%$ PBS/BSA, fixed with 1\% PFA, labeled with anti-SAG1 and an anti-mouse conjugated to Alexa 647 and 
analyzed by flow cytometry. In this way, the percentages of YFP+/SAG1- (genuinely infected DCs) and $\mathrm{YFP}+/ \mathrm{SAG} 1+$ (parasite bound to the plasma membrane) cells were determined as shown in Fig. 3g, $3 \mathrm{~h}$ and Sup. 1a.

Receptor-mediated endocytosis was measured by incubating Scramble and SNX17 KD JAWS-II DCs with $5 \mu \mathrm{g} / \mathrm{ml}$ of anti-H-2 $\mathrm{K}^{\mathrm{b}}$-FITC or anti-OVA/OVA-Alexa 488 conjugates for $30 \mathrm{~min}$ at $4^{\circ} \mathrm{C}$. Then, cells were extensively washed with $0.5 \% \mathrm{PBS} / \mathrm{BSA}$ and incubated in complete medium for $30 \mathrm{~min}$ at $37^{\circ} \mathrm{C}$. After this, DCs were treated with acid buffer stripping solution $(0.5 \mathrm{M} \mathrm{NaCl}$ and $0.5 \%$ acetic acid, $\mathrm{pH} 3)$ for $10 \mathrm{~min}$ on ice, as described before. Finally, cells were washed twice with cold PBS and twice with complete medium, and the MFI of FITC and Alexa 488 were evaluated by flow cytometry.

\section{Immunofluorescence}

Scramble and SNX17 KD JAWS-II DCs were placed on poly-L-lysine-coated glass coverslips during 30 min at room temperature (RT). After one wash with PBS, cells were incubated in complete IMDM medium (supplemented with GM-CSF) alone or with $10 \mu \mathrm{M}$ of latrunculin $\mathrm{B}$ for $1 \mathrm{~h}$ at $37^{\circ} \mathrm{C}$ in an atmosphere of $5 \%$ $\mathrm{CO}_{2}$. After extensive washing with PBS, JAWS-II DCs were first fixed with $2 \%$ PFA during 15 min at $37^{\circ} \mathrm{C}$ and then quenched with $0.2 \mathrm{M}$ glycine. After this, cells were permeabilized with PBS $/ 0.05 \%$ saponin $/ 0.2 \%$ BSA for 20 min at RT, washed and incubated with mouse anti- $\beta$-actin overnight at $4^{\circ} \mathrm{C}$. The next day, cells were washed with permeabilization buffer and incubated with a secondary anti-mouse coupled to Alexa 568 for $45 \mathrm{~min}$ at $4^{\circ} \mathrm{C}$. Cells were washed again three times with permeabilization buffer and twice with PBS, and $60 \mathrm{nM}$ of phalloidin coupled to Alexa 488 diluted in PBS was added for $1 \mathrm{~h}$ at $37^{\circ} \mathrm{C}$. After extensive washing with PBS, coverslips were mounted with ProLong Diamond Anti-Fade (with DAPI). Image acquisition was performed on an Olympus FV-1000 confocal microscope with a 63x/1.4 NA oil immersion objective. One z-stack plane is shown from the acquired images and they were processed with the ImageJ software (Wayne Rasband, National Institutes of Health). Image deconvolution was performed with the Parallel Spectral Deconvolution plugin (Piotr Wendykier) using a theoretical PSF generated by the Diffraction PSF 3D plugin (Robert Dougherty).

\section{Phagosomal isolation}

Scramble and SNX17 KD JAWS-II DCs were pulsed for $20 \mathrm{~min}$ at $18^{\circ} \mathrm{C}$ and $15 \mathrm{~min}$ at $37^{\circ} \mathrm{C}$ with $3 \mu \mathrm{m}$ latex beads. Then, cells were washed once with cold $2 \%$ PBS/BSA and twice with $1 \mathrm{ml}$ of FBS, and chased for the indicated time points with complete GM-CSF-containing medium at $37^{\circ} \mathrm{C}$. After each chase period, DCs were washed once with cold $2 \%$ PBS/BSA to stop phagocytosis and then they were disrupted with a syringe (22G needle) in homogenization buffer (PBS $8 \%$ sucrose, $3 \mathrm{mM}$ imidazole, $1 \mathrm{mM} \mathrm{DTT}$, and $1 \mathrm{X}$ protease inhibitor cocktail) as we have described before in other studies. ${ }^{4,22}$ Samples were centrifuged at $150 \mathrm{~g}$ during $5 \mathrm{~min}$ at $4^{\circ} \mathrm{C}$ and supernatants were placed on a 96-well plate (round bottom). Isolated beads, representing the phagosomal fraction, were washed with cold $2 \%$ PBS/BSA by centrifugation at $1,000 \mathrm{~g}$ during $5 \mathrm{~min}$ at $4^{\circ} \mathrm{C}$ and fixed with $1 \%$ PBS/PFA during $10 \mathrm{~min}$ on ice. After two washes with 0.2 $\mathrm{M}$ glycine and one wash with $2 \% \mathrm{PBS} / \mathrm{BSA}$, samples were labeled $\mathrm{ON}$ at $4^{\circ} \mathrm{C}$ with rabbit anti-OVA and rat 
anti-Lamp1 antibodies. The next day, samples were incubated with the secondary antibodies (anti-rabbit coupled to Alexa 647 and anti-rat coupled to Alexa 488) during $45 \mathrm{~min}$ at $4^{\circ} \mathrm{C}$. Finally, stained phagosomal preparations were analyzed after gating on a particular FSC/SSC region corresponding to single beads in solution.

\section{Statistical analysis}

The Kyplot 6.0 software was used to perform a one-way ANOVA with Dunnett post-test for the qPCR analysis. The two-tailed Student's paired and unpaired t-tests, and the two-way ANOVA with Bonferroni post-test were performed at the indicated Figures by using the GraphPad Prism 5 software. The ImageJ software was used for imaging processing and dendrite size analysis.

\section{Declarations}

\section{Acknowledgements}

This work was supported by the "Agencia Nacional de Promoción Científica y Tecnológica" (PICT 20160013 to IC, PICT 2016-0894 and PICT 2018-4451 to LSM), the EMBO Short Term Fellowship (ASTF 3612013 to IC), the "Centre National de la Recherche Scientifique" (CNRS) with the PICS (Projet International de Coopération Scientifique) collaborative program (TOXORAB 2017 to NB and IC), the "Institut National de la Santé et de la Recherche Médicale", the PIA PARAFRAP Consortium (ANR-11-LABX0024 to NB) and the "Fondation pour la Recherche Médicale" (FDT20170436953 to AS).

\section{Author Contributions}

IC, NB, and LSM conceived, designed and supervised the project. SD and IC performed most of the experiments. CC, AS, FG and SEF performed experiments and provided technical assistance. IC wrote the manuscript. NB and LSM contributed to manuscript editing. All authors discussed results, data analysis and commented on the manuscript preparation.

\section{Conflict of Interest}

The authors declare no competing interests.

\section{References}

1. Kotsias, F., Cebrian, I. \& Alloatti, A. Antigen processing and presentation. Int. Rev. Cell Mol. Biol. 348, 69-121 (2019). 
2. Alloatti, A., Kotsias, F., Magalhaes, J. G. \& Amigorena, S. Dendritic cell maturation and crosspresentation: timing matters! Immunol. Rev. 272, 97-108 (2016).

3. Guermonprez, P. et al. ER-phagosome fusion defines an MHC class I cross-presentation compartment in dendritic cells. Nature 425, 397-402 (2003).

4. Cebrian, l. et al. Sec22b regulates phagosomal maturation and antigen crosspresentation by dendritic cells. Cell 147, 1355-1368 (2011).

5. Montealegre, S. \& van Endert, P. M. Endocytic recycling of MHC class I molecules in non-professional antigen presenting and dendritic cells. Front. Immunol. 9, 3098 (2019).

6. Compeer, E. B., Flinsenberg, T. W., Boon, L., Hoekstra, M. E. \& Boes, M. Tubulation of endosomal structures in human dendritic cells by Toll-like receptor ligation and lymphocyte contact accompanies antigen cross-presentation. J. Biol. Chem. 289, 520-528 (2014).

7. Belabed, M. et al. Kinesin-1 regulates antigen cross-presentation through the scission of tubulations from early endosomes in dendritic cells. Nat. Commun. 11, 1817 (2020).

8. van Weering, J. R. \& Cullen, P. J. Membrane-associated cargo recycling by tubule-based endosomal sorting. Semin. Cell Dev. Biol. 31, 40-47 (2014).

9. Carlton, J., Bujny, M., Rutherford, A. \& Cullen, P. Sorting nexins - unifying trends and new perspectives. Traffic 6, 75-82 (2005).

10. van Weering, J. R., Verkade, P. \& Cullen, P. J. SNX-BAR proteins in phosphoinositide-mediated, tubularbased endosomal sorting. Semin. Cell Dev. Biol. 21, 371-380 (2010).

11. Chandra, M. \& Collins, B. M. The phox homology (PX) domain. Adv. Exp. Med. Biol. 1111, 1-17 (2019).

12. Ghai, R. et al. Structural basis for endosomal trafficking of diverse transmembrane cargos by PXFERM proteins. Proc. Natl. Acad. Sci. U S A 110, E643-652 (2013).

13. Ratcliffe, C. D., Sahgal, P., Parachoniak, C. A., Ivaska, J. \& Park, M. Regulation of cell migration and $\beta 1$ integrin trafficking by the endosomal adaptor GGA3. Traffic 17, 670-688 (2016).

14. Osugi, Y., Fumoto, K. \& Kikuchi, A. CKAP4 regulates cell migration via the interaction with and recycling of integrin. Mol. Cell. Biol. 39, e00073-19 (2019).

15. McNally, K. E. et al. Retriever is a multiprotein complex for retromer-independent endosomal cargo recycling. Nat. Cell Biol. 19, 1214-1225 (2017).

16. Osborne, D. G., Piotrowski, J. T., Dick, C. J., Zhang, J. S. \& Billadeau, D. D. SNX17 affects T cell activation by regulating TCR and integrin recycling. J. Immunol. 194, 4555-4566 (2015).

17. Bergant, M. \& Banks, L. SNX17 facilitates infection with diverse papillomavirus types. J. Virol. 87, 1270-1273 (2013).

18. Fuertes Marraco, S. A. et al. Novel murine dendritic cell lines: a powerful auxiliary tool for dendritic cell research. Front. Immunol. 3, 331 (2012).

19. Poncet, A. F., Blanchard, N. \& Marion, S. Toxoplasma and dendritic cells: an intimate relationship that deserves further scrutiny. Trends Parasitol. 35, 870-886 (2019). 
20. Lopez, J. et al. Intravacuolar membranes regulate CD8 T cell recognition of membrane-bound Toxoplasma gondii protective antigen. Cell Rep. 13, 2273-2286 (2015).

21. Salvioni, A. et al. Robust control of a brain-persisting parasite through MHC I presentation by infected neurons. Cell Rep. 27, 3254-3268 (2019).

22. Cebrian, I., Croce, C., Guerrero, N. A., Blanchard, N. \& Mayorga, L. S. Rab22a controls MHC-I intracellular trafficking and antigen cross-presentation by dendritic cells. EMBO Rep. 17, 1753-1765 (2016).

23. Nair-Gupta, P. et al. TLR signals induce phagosomal MHC-I delivery from the endosomal recycling compartment to allow cross-presentation. Cell 158, 506-521 (2014).

24. Blander, J. M. The comings and goings of MHC class I molecules herald a new dawn in crosspresentation. Immunol. Rev. 272, 65-79 (2016).

25. Blander, J. M. Regulation of the cell biology of antigen cross-presentation. Annu. Rev. Immunol. 36, 717-753 (2018).

26. Montoya, J. G. \& Liesenfeld, O. Toxoplasmosis. Lancet363, 1965-1976 (2004).

27. Wang, Y., Sangaré, L. O., Paredes-Santos, T. C. \& Saeij, J. P. J. Toxoplasmamechanisms for delivery of proteins and uptake of nutrients across the host-pathogen interface. Annu. Rev. Microbiol. 74, 567586 (2020).

28. Santi-Rocca, J. \& Blanchard, N. Membrane trafficking and remodeling at the host-parasite interface. Curr. Opin. Microbiol. 40, 145-151 (2017).

29. Walker, M. E. et al. Toxoplasma gondii actively remodels the microtubule network in host cells. Microbes Infect. 10, 1440-1449 (2008).

30. Frénal, K., Dubremetz, J. F., Lebrun, M. \& Soldati-Favre, D. Gliding motility powers invasion and egress in Apicomplexa. Nat. Rev. Microbiol. 15, 645-660 (2017).

31. Gonzalez, V. et al. Host cell entry by apicomplexa parasites requires actin polymerization in the host cell. Cell Host Microbe 5, 259-272 (2009).

32. Bichet, M. et al. Genetic impairment of parasite myosin motors uncovers the contribution of host cell membrane dynamics to Toxoplasma invasion forces. BMC Biol. 14, 97 (2016).

33. Gaji, R. Y., Huynh, M. H. \& Carruthers, V. B. A novel high throughput invasion screen identifies host actin regulators required for efficient cell entry by Toxoplasma gondii. PLoS ONE8, e64693 (2013).

34. Wu, S. Z. et al. Genome-wide CRISPR screen identifies host factors required by Toxoplasma gondiiinfection. Front. Cell. Infect. Microbiol. 9, 460 (2020).

35. Badour, K. et al. Interaction of the Wiskott-Aldrich syndrome protein with sorting nexin 9 is required for CD28 endocytosis and cosignaling in T cells. Proc. Natl. Acad. Sci. USA 104,1593-1598 (2007).

36. Yarar, D., Waterman-Storer, C. M. \& Schmid, S. L. SNX9 couples actin assembly to phosphoinositide signals and is required for membrane remodeling during endocytosis. Dev. Cell 13, $43-56$ (2007).

37. Shin, N. et al. Sorting nexin 9 interacts with dynamin 1 and N-WASP and coordinates synaptic vesicle endocytosis. J. Biol. Chem. 282, 28939-28950 (2007). 
38. Zhang, J., Zhang, X., Guo, Y., Xu, L. \& Pei, D. Sorting nexin 33 induces mammalian cell micronucleated phenotype and actin polymerization by interacting with Wiskott-Aldrich syndrome protein. J. Biol. Chem. 284, 21659-21669 (2009).

39. Wang, J. et al. Endosomal receptor trafficking: retromer and beyond. Traffic 19, 578-590 (2018).

40. Lou, J. et al. SNX10 promotes phagosome maturation in macrophages and protects mice against Listeria monocytogenes infection. Oncotarget 8, 53935-53947 (2017).

41. Chua, R. Y. \& Wong, S. H. SNX3 recruits to phagosomes and negatively regulates phagocytosis in dendritic cells. Immunology 139, 30-47 (2013).

42. Klose, M., Salloum, J. E., Gonschior, H. \& Linder, S. SNX3 drives maturation of Borrelia phagosomes by forming a hub for PI(3)P, Rab5a, and galectin-9. J. Cell Biol. 218, 3039-3059 (2019).

43. Lim, J. P., Teasdale, R. D. \& Gleeson, P. A. SNX5 is essential for efficient macropinocytosis and antigen processing in primary macrophages. Biol. Open 1, 904-914 (2012).

\section{Figures}


Fig. 1
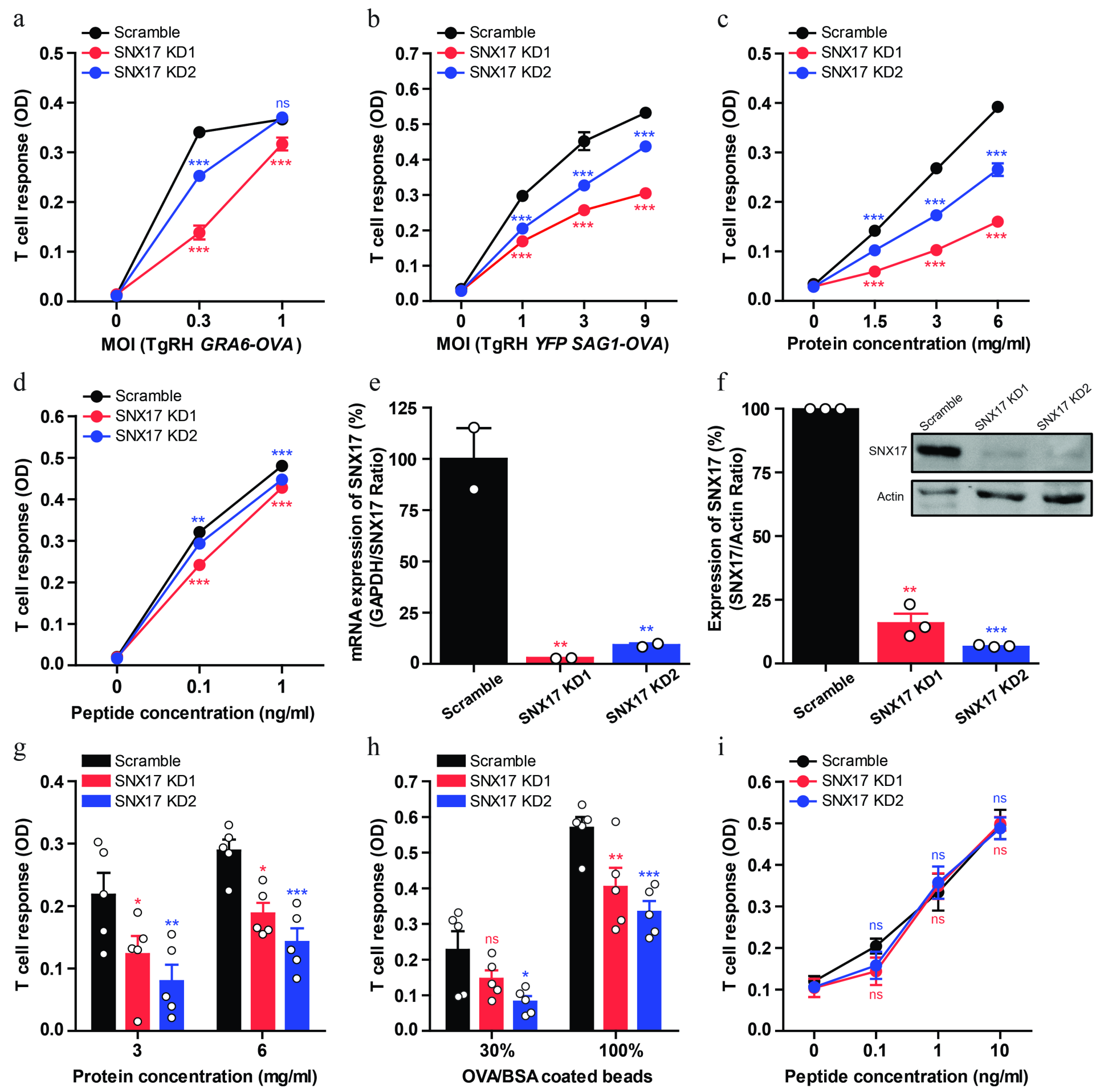

Figure 1

SNX17 silencing inhibits antigen cross-presentation by DCs. a-b) The cross-presentation of the SIINFEKL peptide (a) appended at the C-terminus of the GRA6 antigen expressed by T. gondii (TgRH GRA6-OVA) or (b) incorporated within the SAG1-OVA antigen expressed by the parasite (TgRH YFP SAG1-OVA) by MutuDCs previously transduced with Scramble, SNX17 KD1 or SNX17 KD2 shRNA, was evaluated $8 \mathrm{~h}$ post-infection at the indicated $\mathrm{MOI}$ with the B3Z T cell hybridoma. Data represent mean \pm SEM of triplicate values from one experiment (a larger screening). $P>0.05$ (ns) and ${ }^{* \star *} P<0.001$. A two-way 
ANOVA and the Bonferroni post-test were performed. c-d) The cross-presentation ability after incubation with (c) soluble OVA protein or (d) the SIINFEKL control peptide at the indicated concentrations by MutuDCs previously transduced with Scramble, SNX17 KD1 or SNX17 KD2 shRNA, was evaluated with the B3Z T cell hybridoma. Data represent mean \pm SEM of triplicate values from one experiment (a larger screening). ${ }^{* * P}<0.01$ and ${ }^{*} * \mathrm{P}<0.001$. A two-way ANOVA and the Bonferroni post-test were performed. e) RT-qPCR quantification of SNX17 mRNA in MutuDCs transduced with lentiviruses encoding a random sequence (Scramble) and two shRNA targeting SNX17 (KD1 and KD2). Data show mean \pm SEM of duplicate values from one experiment (a larger screening). ${ }^{\star \star} P<0.01$. A one-way ANOVA and the Dunnett post-test were performed. f) Immunoblotting and densitometry quantification of SNX17 in JAWS-II DCs infected with the same lentivirus used in (e). Data show mean \pm SEM of three independent experiments. ${ }^{\star \star} P=0.0020$ and ${ }^{\star \star \star} P<0.0001$. The two-tailed Student's paired t-test was performed. $\left.g-i\right)$ The crosspresentation ability of JAWS-II DCs transduced with Scramble, SNX17 KD1 or SNX17 KD2 shRNA, after incubation with (g) soluble OVA, (h) OVA/BSA-coated beads, and (i) the SIINFEKL control peptide at the indicated concentrations was evaluated with the B3Z T cell hybridoma. Data represent mean \pm SEM of three independent experiments $(n=5)$. $P>0.05(n s),{ }^{\star} P<0.05$, ${ }^{\star *} P<0.01$ and ${ }^{*} * P<0.001$. A two-way ANOVA and the Bonferroni post-test were performed. 
Fig. 2
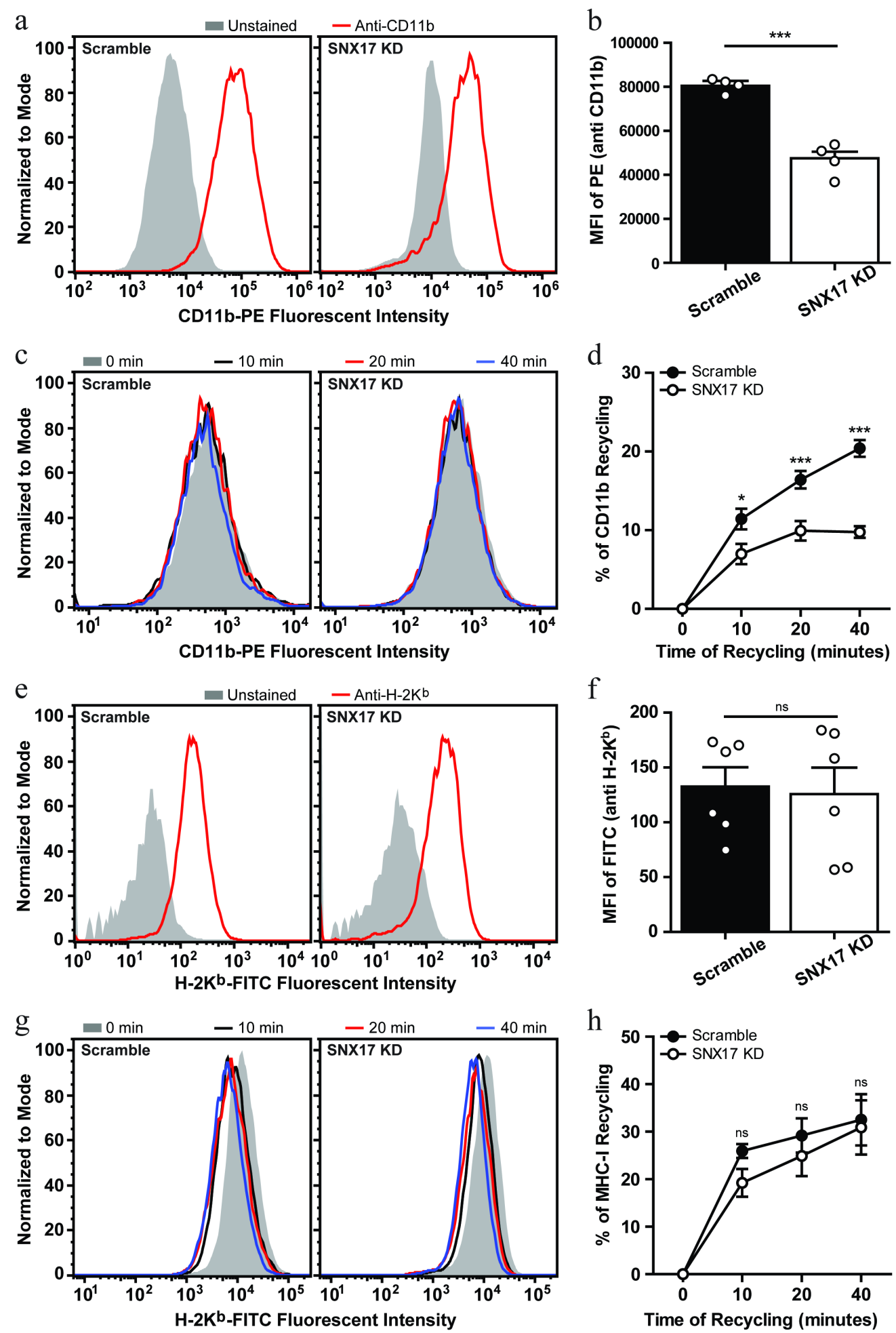

Figure 2

The recycling of CD11b integrin, but not of MHC-I molecules, is impaired in SNX17 KD DCs. a-b) FACS analysis of CD11b at the cell surface of JAWS-II DCs. a) Representative FACS profile of Scramble (left panel) and SNX17 KD (right panel) cells after CD11b staining. b) The histograms show the stained/unstained ratio of the MFI of PE-conjugated anti-CD11b antibody and data represent mean \pm SEM of two independent experiments $(n=4) .{ }^{* \star *} P=0.0002$. The two-tailed Student's unpaired t-test was 
performed. $c-d) C D 11 b$ integrin recycling ability was measured by FACS at the indicated time periods by the same cells analyzed in (a). c) Representative FACS profiles of anti-CD11b (PE) recycling by Scramble (left panel) and SNX17 KD (right panel) JAWS-II DCs. d) The curves show the percentage of anti-CD11b $(P E)$ recycling over time and data represent mean \pm SEM of four independent experiments $(n=4)$. $P<$ 0.05 and ${ }^{* \star *} \mathrm{P}<0.001$. A two-way ANOVA and the Bonferroni post-test were performed. e-f) FACS analysis of MHC-I molecules labeled at the cell surface of the same cells analyzed in (a). e) Representative FACS profile of Scramble (left panel) and SNX17 KD (right panel) JAWS-II DCs after MHC-I staining. b) The histograms show the stained/unstained ratio of the MFI of FITC conjugated anti-H-2Kb antibody and data represent mean \pm SEM of three independent experiments $(n=6)$. $P=0.8266$ (ns). The two-tailed Student's unpaired t-test was performed. $\mathrm{g}$-h) MHC-I molecules recycling ability was measured by FACS at the indicated time periods by the same cells analyzed in (a). g) Representative FACS profiles of anti-H2Kb antibody (FITC) recycling by Scramble (left panel) and SNX17 KD (right panel) JAWS-II DCs. h) The curves show the percentage of anti-H-2Kb (FITC) recycling over time and data represent mean \pm SEM of four independent experiments $(n=4)$. P $>0.05(n s)$. A two-way ANOVA and the Bonferroni post-test were performed. 
Fig. 3
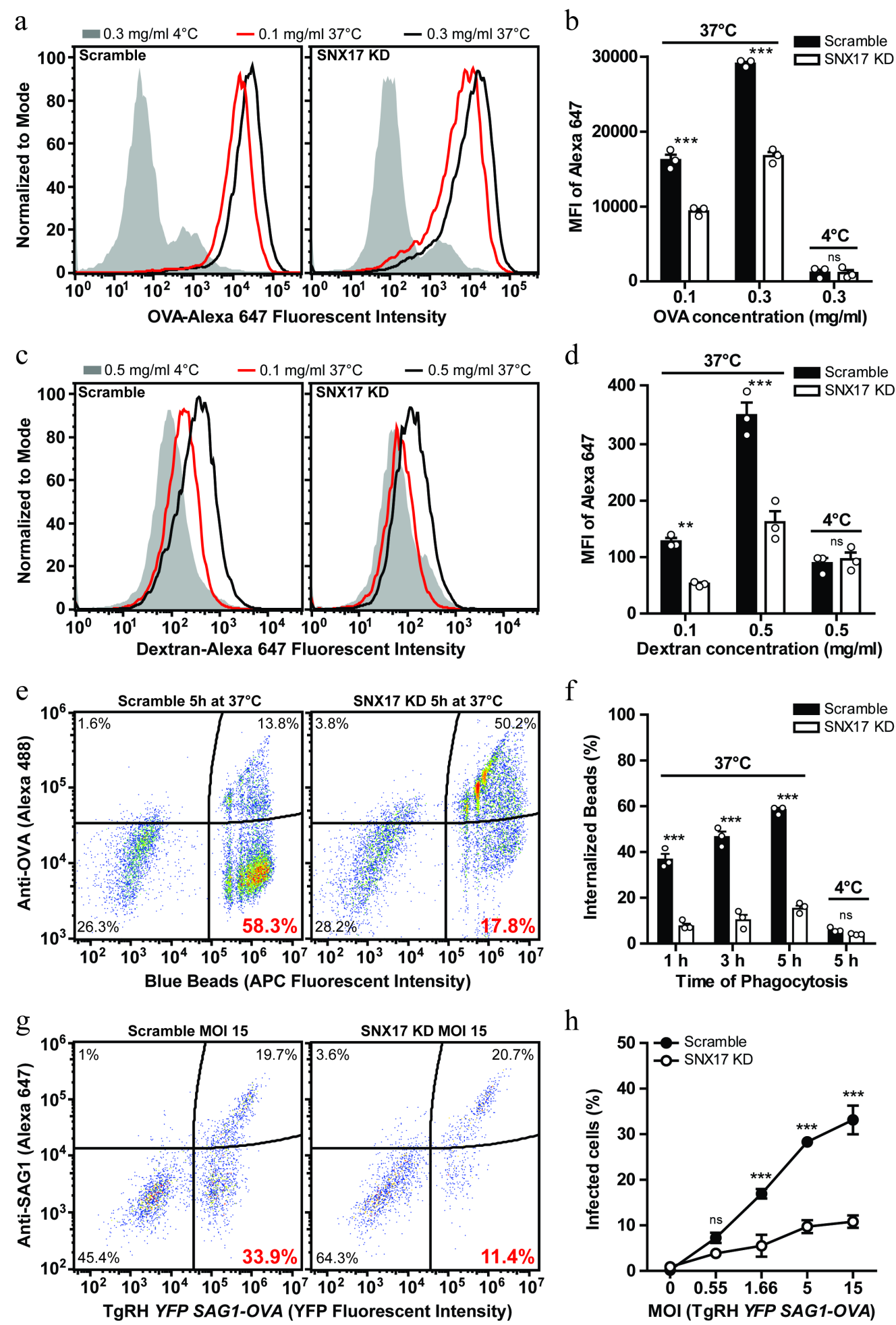

Figure 3

SNX17 controls fluid-phase endocytosis, phagocytosis and T. gondii invasion in DCs. a-d) Scramble and SNX17 KD JAWS-II DCs were incubated during $1 \mathrm{~h}$ with the indicated concentrations of fluorescent a) OVA or C) dextran and fluid-phase endocytosis was assessed. Antigen internalization was conducted at $37^{\circ} \mathrm{C}$ for effective uptake and at $4^{\circ} \mathrm{C}$ with the highest concentration as negative control. In a) and c) representative FACS histograms show the fluorescent intensities of Alexa 647 at the different conditions 
used. $\ln b$ ) and d) data represent mean \pm SEM of triplicate values and are representative of three independent experiments. $P>0.05$ (ns), ${ }^{\star *} \mathrm{P}<0.01$ and ${ }^{\star * *} \mathrm{P}<0.001$. A two-way ANOVA and the Bonferroni post-test were performed. e-f) Scramble and SNX17 KD JAWS-II DCs were incubated during 1, 3 and $5 \mathrm{~h}$ with $3 \mu \mathrm{m}$ fluorescent latex beads and the phagocytic capacity of these cells was measured. Phagocytosis was performed at $37^{\circ} \mathrm{C}$ for effective uptake and at $4^{\circ} \mathrm{C}$ during the longest period of internalization as negative control. e) Representative FACS histograms of the condition $5 \mathrm{~h}$ at $37^{\circ} \mathrm{C}$ showing the APC+/OVA- regions that indicate the percentages of effective particle uptake (numbers in red). $f$ ) Data represent mean \pm SEM of triplicate values and are representative of three independent experiments. $\mathrm{P}>0.05$ (ns) and $* \star * P<0.001$. A two-way ANOVA and the Bonferroni post-test were performed. $g$-h) Scramble and SNX17 KD JAWS-II DCs were infected with the indicated MOI of TgRH YFP SAG1-OVA during $3 \mathrm{~h}$ at $37^{\circ} \mathrm{C}$ and parasite infection was assessed. $\mathrm{g}$ ) Representative FACS histograms of the condition MOI 15 showing the YFP+/SAG1- regions that indicate the percentages of effective T. gondii infection (numbers in red). h) Data represent mean \pm SEM of triplicate values and are representative of two independent experiments. $\mathrm{P}>0.05(\mathrm{~ns})$ and $* * * \mathrm{P}<0.001$. A two-way ANOVA and the Bonferroni posttest were performed. 
Fig. 4

a
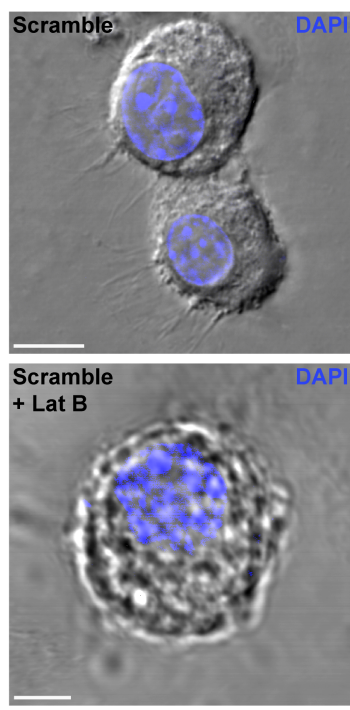

b
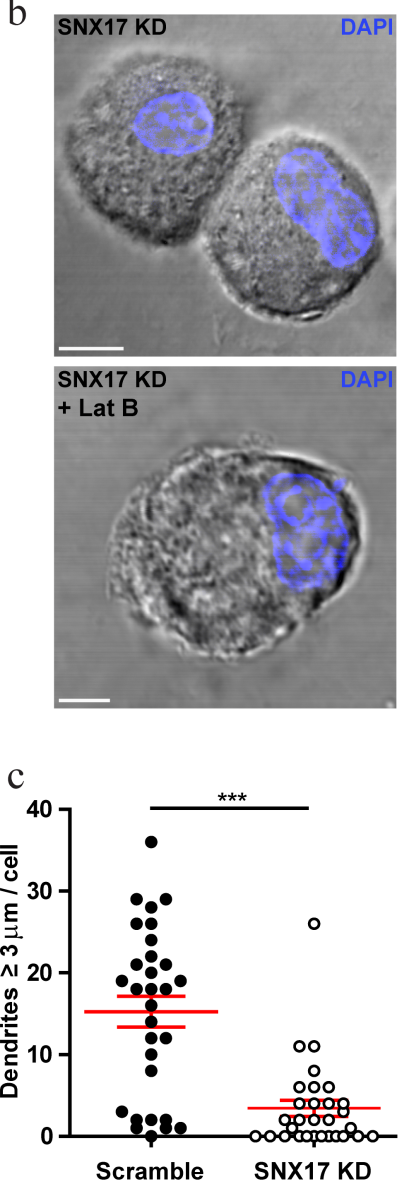
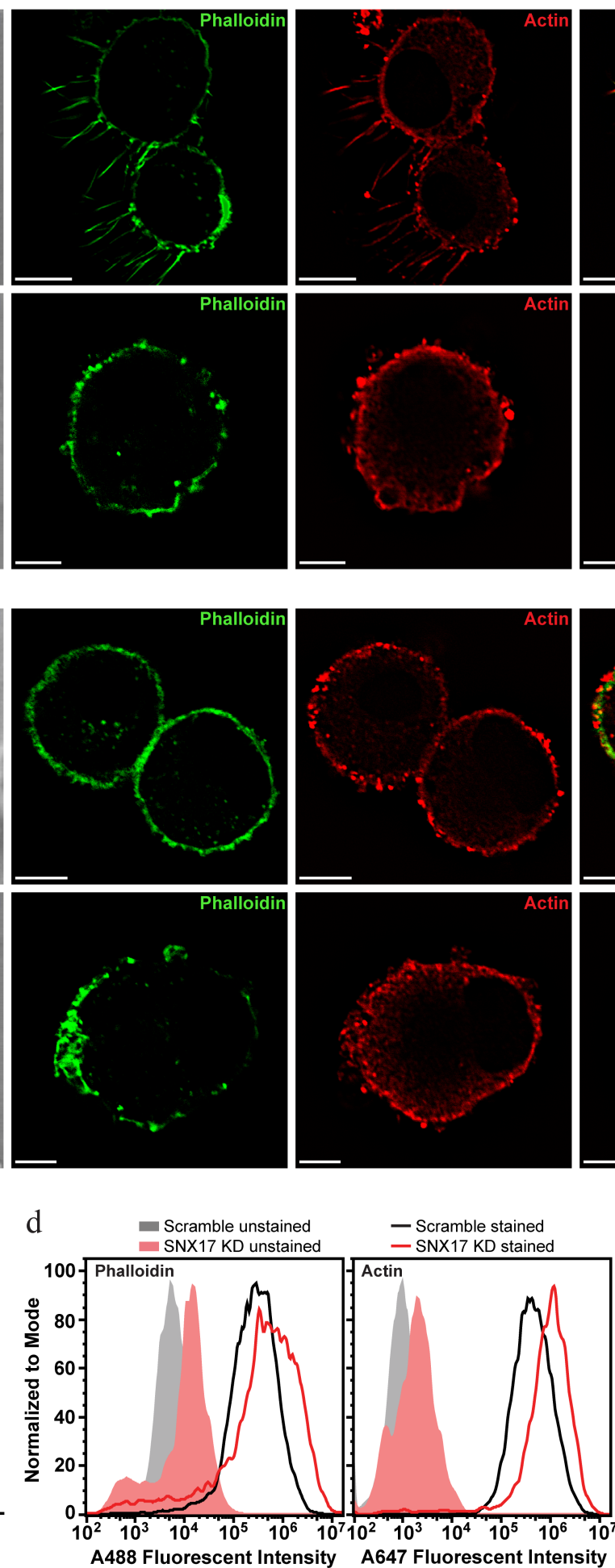
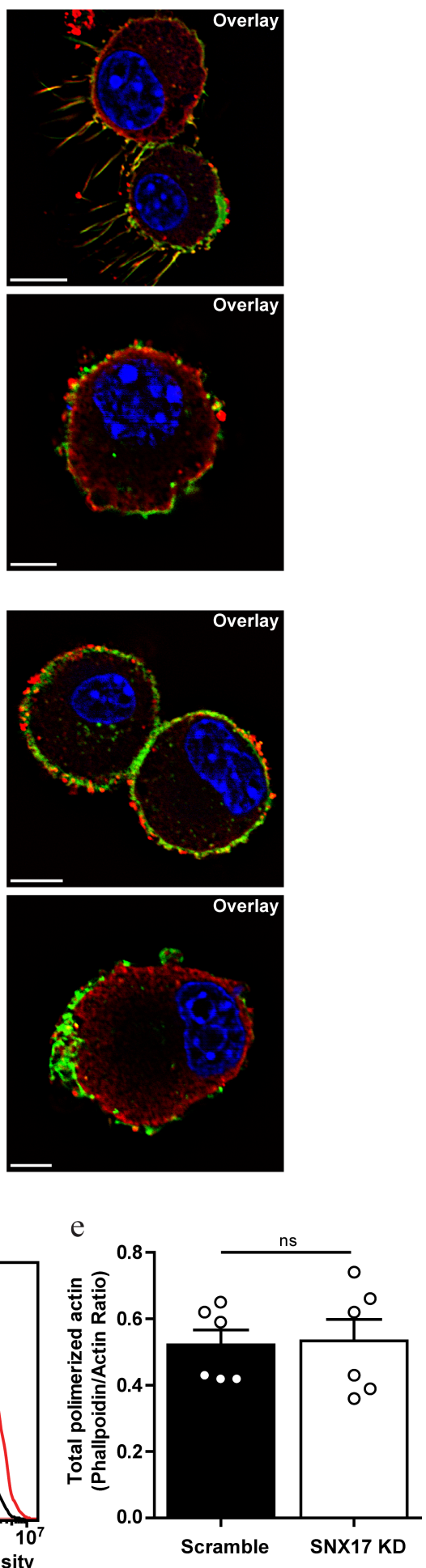

Figure 4

The actin cytoskeleton is not properly organized in SNX17 KD DCs. a-b) Immunofluorescence labeling and confocal microscopy analysis showing the distribution of F-actin (phalloidin, green) and total actin (anti- $\beta$-actin, red) in a) Scramble and b) SNX17 KD JAWS-II DCs. Disruption of actin polymerization was achieved by the treatment with latrunculin B (Lat B, lower panels). Nuclei stained with DAPI and DIC images are shown on the left. Overlay of all fluorescent channels is shown in the right panels. Scale bars: 
$10 \mu \mathrm{m}$. Data are representative of 30 images analyzed for each experimental condition from three independent experiments. c) Quantification showing the number of $3 \mu \mathrm{m}$ dendrites, or longer, per cell from Scramble and SNX17 KD JAWS-II DCs. The ImageJ software was used for this analysis. Red lines show mean \pm SEM of three independent experiments $(n=30)$. ${ }^{\star \star \star} P<0.0001$. The two-tailed Student's unpaired t-test was performed. d-e) JAWS-II DCs were labeled with phalloidin coupled to Alexa 488 and anti- $\beta$-actin (a secondary antibody coupled to Alexa 647 was used) to detect F-actin and total actin, respectively, and analyzed by flow cytometry. d) Representative FACS histograms showing unstained and stained Scramble (black lines) and SNX17 KD (red lines) cells. e) The total amount of actin polymerized was determined by analyzing the ratio F-actin/total actin. Data show mean \pm SEM of two independent experiments $(n=6) . P=0.8856(n s)$. The two-tailed Student's unpaired t-test was performed. 
Fig. 5
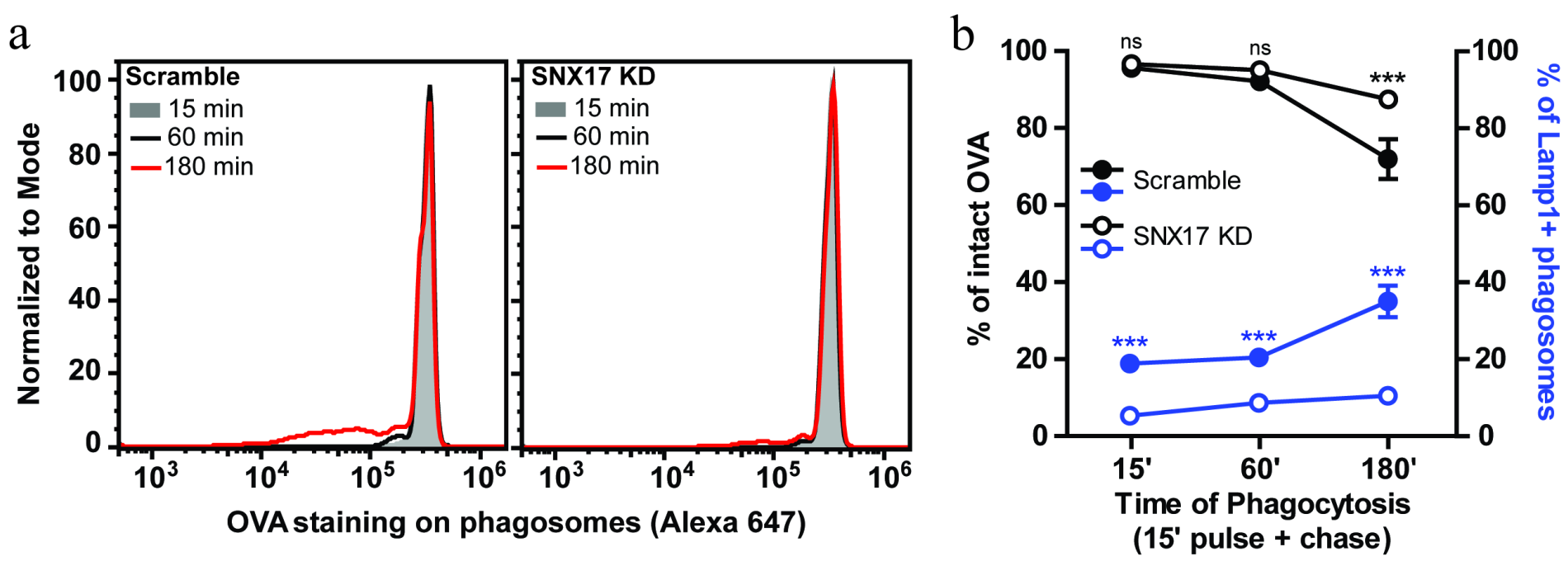

C

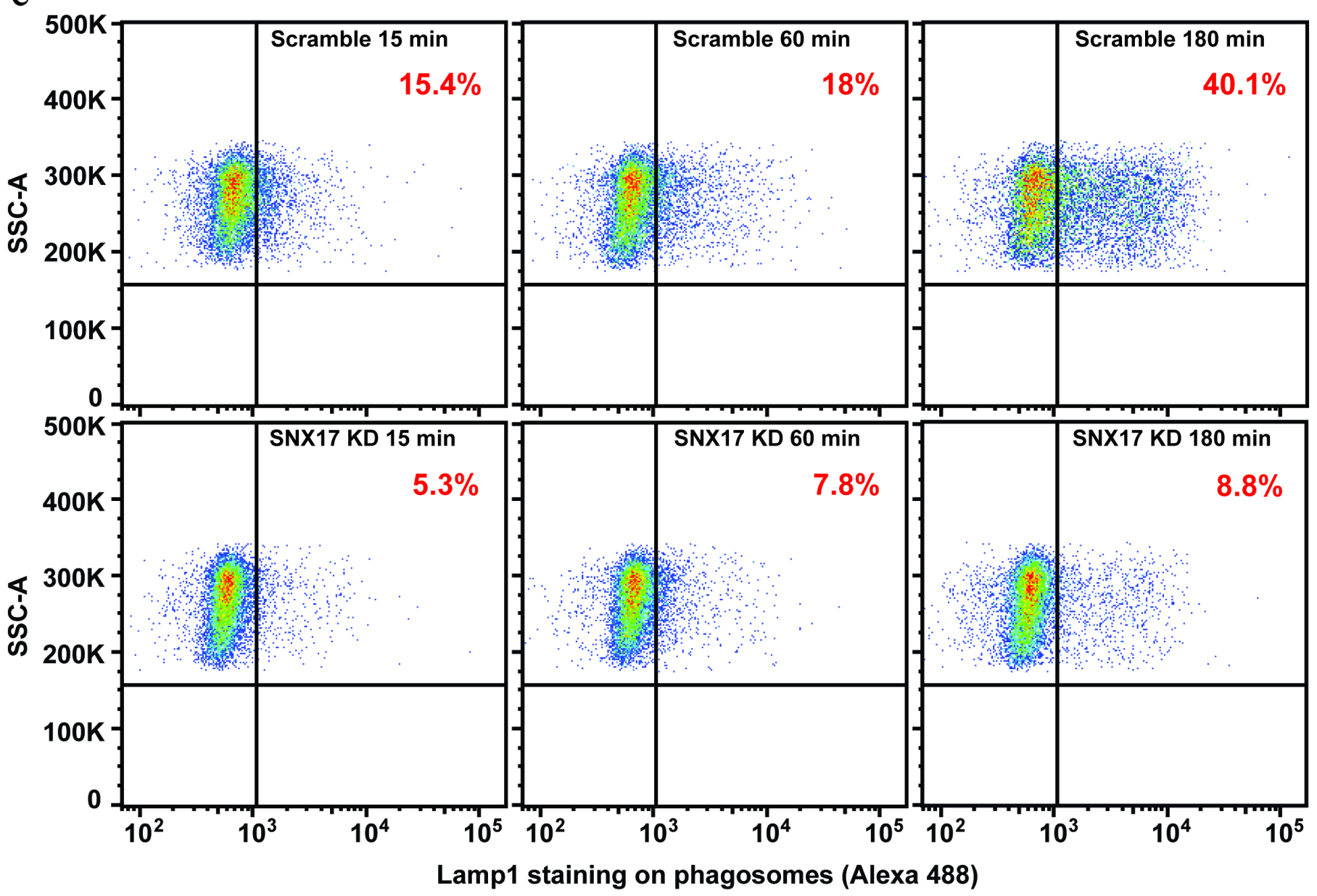

Figure 5

SNX17 regulates phagosomal maturation by DCs. a) Representative FACS profiles showing the OVA staining on isolated phagosomes of 15 (grey), 60 (black) and 180 (red) min post-internalization of $3 \mu \mathrm{m}$ latex beads from Scramble (left) and SNX17 KD (right) JAWS-II DCs. Data are representative of three independent experiments. b) The kinetics of OVA degradation, as percentage of intact OVA (black lines, left axis), and Lamp1 acquisition (blue lines, right axis) in isolated phagosomes at the indicated time 
periods post-internalization from Scramble and SNX17 KD JAWS-II DCs was assessed by FACS analysis. Data show mean \pm SEM of three independent experiments $(n=6)$. $P>0.05(n s)$ and ${ }^{\star *} P<<0.001$. A twoway ANOVA and the Bonferroni post-test were performed. c) Representative FACS profiles showing Lamp1 staining on isolated phagosomes at the indicated time periods after $3 \mu \mathrm{m}$ latex beads internalization by Scramble (upper panels) and SNX17 KD (lower panels) JAWS-II DCs. Upper right quadrants indicate the percentages of Lamp1+ phagosomes (red numbers) at the different time points analyzed. Data are representative of three independent experiments.

\section{Supplementary Files}

This is a list of supplementary files associated with this preprint. Click to download.

- FigureSup.1.tif 